This study was supported by grants from the US Public Health Service and the Health Research Council of the City of New York.

Rockefeller University,

Adrian LeE*

JAMES GORDON

René Dubos

New York.

Received October 17, 1968 .

* Present address: Department of Medical Microbiology, University of New South Wales, Sydney, Australia.

${ }^{1}$ Dubos, R., Schaedler, R. W., Costello, R., and Hoet, P., J. Exp. Med., 122, 67 (1965).

2 Dubos, R., Carworth Europe Collected Papers, 2, 11 (1968).

${ }^{3}$ Dubos, R., Gastroenterology, 51, 868 (1966).

- Savage, D. C., and Dubos, R., J. Exp. Med., 128, 97 (1968).

Savage, D. C., Dubos, R., and Schaedler, R. W., J. Exp. Med., 127, 67 (1968).

${ }^{6}$ Hungate, R. E., Bact. Rev., 14, 1 (1950).

? Drasar, B. S., J. Pathol. Bact., 94, 417 (1967).

${ }^{8}$ Aranki, A., Syed, S. A., and Freter, R., Baet. Proc., 68, 94 (1968).

- Schaedler, R. W., Dubos, R., and Costello, R., J. Exp.Med.,122, 59 (1965).

\section{Method for the Routine Preservation of Micro-organisms}

WHEN carrying out experiments with micro-organisms over a long period of time, say 5 years, it is extremely difficult to ensure that the source material remains unchanged. One method is to prepare a large number of ampoules of the freeze-dried micro-organisms and to use these for inoculation of cultures as required, but the large storage space necessary presents a difficulty, especially if more than one species of micro-organism is to be preserved. The number of ampoules necessary can be decreased if each ampoule is used to inoculate a cooked meat medium ${ }^{1}$, which is then cultured and stored at $4^{\circ} \mathrm{C}$, but this method has limitations: viability decreases in cooked meat broth, and fresh broths have to be inoculated at intervals of about 3 months.

This communication describes a simple method which overcomes these difficulties, based on a rapid freeze in liquid nitrogen followed by storage at $-70^{\circ} \mathrm{C}$. A culture is prepared with the inoculum from a freeze-dried sample or other suitable source. Using a pipette which delivers $36 \mathrm{drops} / \mathrm{ml}$., drops of culture are allowed to fall into a Dewar flask containing liquid nitrogen. On freezing, the drops sink to the bottom of the flask. When 300 or more frozen drops have formed, they are transferred to a container previously cooled to $-70^{\circ} \mathrm{C}$, and maintained at this temperature until required. The procedure is then to remove a single frozen drop with chilled sterile forceps and to put the drop into an empty sterile test tube. After rapid thawing the suspension formed can be used either to inoculate a nutrient agar plate by "stroking" with a sterile loop, or to inoculate a growth medium direct. With the former method the nutrient agar plate is incubated overnight, and a sterile loop is used to remove samples for inoculation of growth media. In practice, the plate method is preferable because it enables the sterility to be checked and also a plate can be used for inoculations for 1-2 weeks, so reducing the number of frozen pellets required within a given time.

Fig. 1 shows how the viability of Escherichia coli B decreases with storage time. After nearly 2 years, 30 per cent of the population remained viable. For comparison, freeze-drying of $E$. coli $\mathrm{B}$ followed by storage at $4^{\circ} \mathrm{C}$ for 18 months gave a viability of only 8 per cent. Thus the new method is superior as a means of preserving viability and the selection of variants is therefore less likely. It is possible that protecting agents such as dimethyl sulphoxide, glycerol and raffinose added to the suspension before coeling might enhance survival. E. coli K12 HfrC

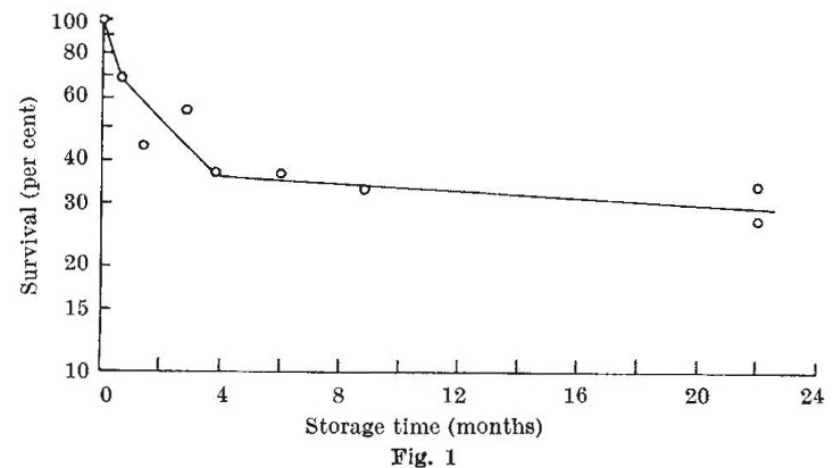

and $E$. coli $\mathrm{K} 12 \mathrm{HfrH}$ have also been successfully stored for nearly a year by the method described.

Although not examined in detail, the temperature of storage is important. $E$. coli $\mathrm{K} 12 \mathrm{HfrC}$ stored at $-15^{\circ} \mathrm{C}$ lost viability very rapidly (about 1 month for sterility) as compared with storage at $-70^{\circ} \mathrm{C}(80$ per cent viability after 1 month). If a $-70^{\circ} \mathrm{C}$ refrigerator is not available an alternative is to use solid carbon dioxide or a liquid nitrogen storage container. Care should be exercised with carbon dioxide, however, because unless the pellet is well sealed, carbon dioxide dissolves into the frozen pellet and can cause a severe change in $p \mathrm{H}$ especially on thawing.

I thank Mr C. M. Saunders for technical assistance.

Microbiological Research Establishment,

C. S. $\mathrm{Cox}^{*}$

Porton Down,

Wiltshire.

Received November 16, 1968.

* Present address: Fort Detrick, Frederick, Maryland, USA.

'The Oxoid Manual, third ed. (Oxoid Ltd, 1965).

\section{Oncogenicity of Mixtures of Adeno-associated Virus and Adenovirus Type 12}

WE reported recently ${ }^{1}$ that purified adeno-associated viruses (types 1 and 2 ) did not influence the oncogenicity of adenovirus 12 when mixtures were inoculated into newborn hamsters. Kirschstein et al. ${ }^{2}$ have reported contradictory results in very similar experiments. We were kindly informed (by Dr M. D. Hoggan, National Institutes of Health) that the preparations we used for purification consistently showed low or no infectivity titres, despite containing high concentrations of particles banding at the appropriate density.

While we have no precise explanation for the low infectivity of these preparations, we feel that this offers the most likely explanation for the difference in results. The crucial factor is thus presumed to be infectivity and not simply the presence of physical particles.

\section{RAYMOND V. GILDEN \\ JEROME KERN \\ Theodore G. Beddow}

Flow Laboratory Incorporated, Rockville, Maryland.

Laboratory of Viral Diseases,

ROBERT J. HUEbner

National Institute of Allergy and Infectious Diseases,

National Institutes of Health,

Bethesda, Maryland.

Received November 1, 1968.

${ }^{1}$ Gilden, R. V., Kern, J., Beddow, T. G., and Huebner, R. J., Nature, 219, 80 (1968)

${ }^{2}$ Kirschstcin, R. L., Smith, K. O., and Peters, E. A., Proc. Soc. Exp. Biol. and Med., 128, 670 (1968). 